\title{
Optimized Spacing Of The Longitudinal Reinforcement In CRCP To Avoid Horizontal Cracking
}

\author{
Muhammad Kashif $^{\mathrm{a}, 1}$, Pieter De Winne ${ }^{\mathrm{b}}$, Muhammad Wisal Khattak $^{\mathrm{a}}$, Amelie Outtier ${ }^{\mathrm{c}}$, and Hans De Backer ${ }^{\mathrm{d}}$

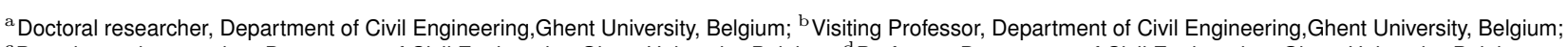 \\ ${ }^{\mathrm{c}}$ Post-doctoral researcher, Department of Civil Engineering,Ghent University, Belgium; ${ }^{\mathrm{d}}$ Professor, Department of Civil Engineering, Ghent University, Belgium \\ This manuscript is licensed under the CC BY-SA 4.0 License.
}

Continuously reinforced concrete pavement (CRCP) is characterized by the absence of transverse contraction joints and the presence of longitudinal and transverse reinforcement. The continuous longitudinal reinforcement holds the transverse cracks, caused by the longitudinal shrinkage of concrete, tightly together and thus provides long term performance with minimal maintenance cost. Field investigations on recently constructed CRCP's in Flanders region of Belgium indicated horizontal cracking in the vicinity of the longitudinal reinforcement under the transverse cracks which eventually causes the punch-out distress at the edge of the pavement slab.

This paper shows the results of a finite element (FE) study to investigate the effect of varying longitudinal reinforcement on the risk of horizontal cracking in CRCP under typical Flanders conditions. For this purpose, a (3D) FE model of CRCP is developed using a FE package Diana 10.2. The varying longitudinal reinforcement with a most narrow spacing of $125 \mathrm{~mm}$ in the outer region of the pavement slab is applied while keeping the same CRCP reinforcement ratio. A comparison is made with the conventional longitudinal reinforcement spacing $(170 \mathrm{~mm})$. Development of concrete stress in the vicinity of the longitudinal reinforcement is plotted against the different longitudinal steel spacing. Findings show that the stress in concrete near longitudinal reinforcement is significantly reduced up to maximum $17 \%$ when the narrow spacing is used. In addition, the steel stress in the longitudinal reinforcing is reduced up to maximum $31.75 \%$ in the outer region of the pavement slab.

Horizontal cracking | CRCP | Longitudinal reinforcement spacing | 3D FE analysis

\section{Introduction}

A continuously reinforced concrete pavement (CRCP) is a type of rigid pavement which is constructed without any transverse contraction joints with the exception of possible construction joints. CRCP has embedded steel in transverse and longitudinal directions. Transverse cracking is allowed to form freely as a result of dry shrinkage but the cracks are held tightly together with continuous longitudinal reinforcing steel, ensuring an optimal crack pattern providing good ride quality. This type of pavement is mostly preferred for high priority routes because of the low maintenance requirements $[1,2]$.

Previous field studies indicated that punch-out is the most severe structural distress in CRCPs [3-8]. During the mid1980s, Texas Department of Transportation addressed this distress by modifying the design and construction practices. It has been observed that punch-out forms at the edge of the concrete slab due to the formation of two transverse cracks connected by a horizontal crack in the vicinity of longitudinal reinforcement. This formation ultimately leads to a half-depth punch-out in CRCP. Studies on the mechanism of horizontal cracking revealed that the longitudinal reinforcing steel significantly influences the formation of horizontal cracking. A significant amount of tensile stress in concrete in the vicinity of longitudinal steel developed due to the environmental load and steel restraint. It was also reported that the horizontal cracking may be affected by variations in the concrete material properties, environmental conditions and reinforcement layout $[1,9]$.

Belgium has used continuously reinforced concrete pavements (CRCPs) on a very large scale for a very long time [2, 10]. For more than 40 years, Belgium has been using CRCP to build the motorway network and other high priority roads. The proponents of CRCPs cite durability, sustainability and low maintenance which made it as long-lasting applications. Field surveys of several newly constructed CRCPs under the current design concept 3 in Belgium, showed the horizontal cracks in concrete following the longitudinal reinforcement at the transverse crack interface during the early ages [11-15]. Although, several changes were made in design concepts as shown in Table 1 [15] by modifying the amount of reinforcement and the slab thickness. However, horizontal cracking has not been well addressed yet in Belgium.

Therefore, the present research is conducted to develop a 3D FE model for studying the horizontal cracking in CRCP under Belgian environmental conditions. For this purpose, two different layouts of longitudinal reinforcement placement; (1) varying longitudinal reinforcement spacing (2) conventional longitudinal reinforcement spacing in accordance with the current design concept 3 in Belgium, are applied to analyze the development of tensile stress in concrete in the vicinity of the longitudinal reinforcement.

Due to the higher traffic intensity, the thickness in concept 3 has been increased since approximately the year 2010 up to 230 $\mathrm{mm}$ concrete thickness, with an identical reinforcement percentage of $0.75 \%$, which implies a longitudinal reinforcement Ø20 every $170 \mathrm{~mm}$ [16].

To further optimize the crack pattern in the current design concept 3 , the active crack control technique was introduced in the year 2012 in Belgium, by making a saw cut at the edge of the concrete strip, $400 \mathrm{~mm}$ long, $40 \mathrm{~mm}$ deep, spaced at $1200 \mathrm{~mm}$, within 24 hours after concreting (when brushing off the concrete mortar for exposed aggregate finishing). This is a simple and efficient technique which ensures a faster

\footnotetext{
Authors declare no conflict of interest with the material in this manuscript.

${ }^{1}$ To whom correspondence should be addressed. E-mail: muhammad.kashif@ugent.be
} 
Table 1. Overview of design concepts for CRCP in Belgium

\begin{tabular}{|c|c|c|c|}
\hline Design concept & Concept 1 & Concept 2 & Concept 3 \\
\hline Period & $1970-1981$ & $1981-1995$ & 1995 -onwards \\
\hline$\%$ longitudinal reinforcement & $0.85 \%(\varnothing 18 \mathrm{~mm}$ every $150 \mathrm{~mm})$ & $0.67 \%(\varnothing 16 \mathrm{~mm}$ every $150 \mathrm{~mm})$ & $0.75 \%$ (Ø20mm every $170 \mathrm{~mm})$ \\
\hline Distance of reinforcement to surface & $60 \mathrm{~mm}$ & $90 \mathrm{~mm}$ & $80 \mathrm{~mm}$ \\
\hline Concrete thickness & $200 \mathrm{~mm}$ & $200 \mathrm{~mm}$ & $230 / 250 \mathrm{~mm}$ \\
\hline Intermediate layer in asphalt & Yes, $60 \mathrm{~mm}$ & No & Yes, $50 \mathrm{~mm}$ \\
\hline Surface finish & Transverse grooved & Transverse grooved or chemical exposed aggregate surface & Fine exposed aggregate surface \\
\hline Air-entrainment & No & No & Yes \\
\hline
\end{tabular}

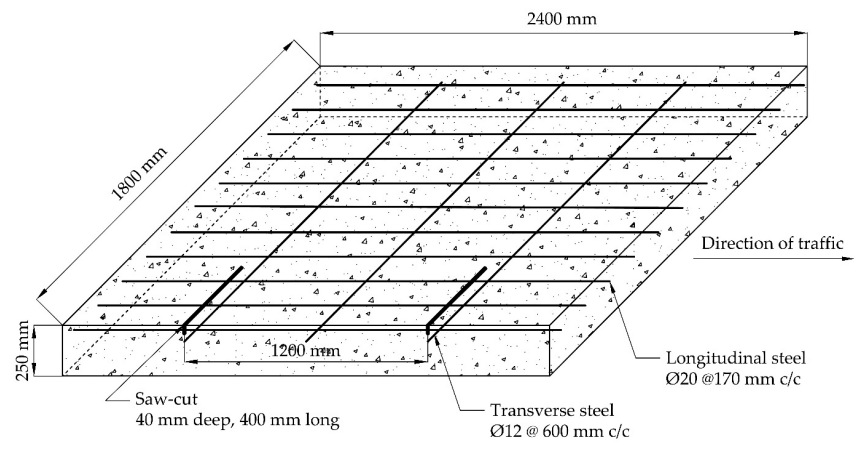

Fig. 1. Geometry of CRCP segment

crack development, straighter and more regular cracks with significantly reduced risk of clustering. It has been monitored that up to $80 \%$ of the cracks are initiated by a saw cut [17].

\section{Finite element modeling of CRCP}

A. Geometry. Rectangular saw cut following the dimensions of $4 \mathrm{~mm}$ (width) x $40 \mathrm{~mm}$ (depth) $\mathrm{x} 400 \mathrm{~mm}$ length is considered in FE model to induce the active cracks to capture the crack pattern. The length, width and depth of the CRCP segment are assumed as $2400 \mathrm{~mm}, 1800 \mathrm{~mm}$ and $250 \mathrm{~mm}$ respectively. The spacing between the saw cuts is taken as $1200 \mathrm{~mm}$. Two different layouts of longitudinal reinforcement placement are adopted. In the first layout, a steel bar of $20 \mathrm{~mm}$ diameter is placed at a uniform spacing of $170 \mathrm{~mm} \mathrm{c} / \mathrm{c}$ (conventional steel spacing) which complies to the current design concept 3 of CRCP in Belgium. In the second layout, the spacing of steel in the edge region of the concrete slab is assumed as $125 \mathrm{~mm}$ c/c. Further to the middle, the spacing is increased to 170 $\mathrm{mm} \mathrm{c} / \mathrm{c}$ in the central part of the model. The last two bars are placed at a spacing of $225 \mathrm{~mm} \mathrm{c} / \mathrm{c}$. The reinforcement ratio in both layouts is kept the same. The reinforcement layout of CRCP segment is shown in Figure 1.

The behavior of CRCP can be assumed to be symmetric with respect to the center of the two adjacent transverse cracks as well as with respect to the center of the lane under environmental loading $[4,18,19]$. Therefore, one-half of the slab is considered on either side of saw-cuts and other half of the lane is taken into account by considering the proper boundary conditions. 3D FE models of CRCP segment are illustrated in Figure 2.

B. Material model. Among the different alternatives provided by Diana FE software, the Euro-code model is used as a reference model, where the required parameters are modified for a more accurate mimicking of the real material. In order
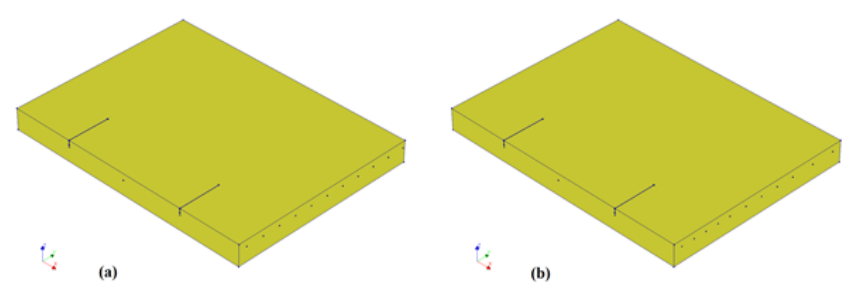

Fig. 2. (a) 3D FE model with conventional steel spacing (b) 3D FE model with varying steel spacing

Table 2. Material input parameters

\begin{tabular}{ll}
\hline Elastic modulus of concrete & $24654.3 \mathrm{MPa}$ \\
Elastic modulus of steel & $200,000 \mathrm{MPa}$ \\
Mean compressive strength of concrete & $48 \mathrm{MPa}$ \\
Mean tensile strength of concrete & $3.51 \mathrm{MPa}$ \\
Coefficient of thermal expansion of concrete & $10.0 \times 10-6\left(1 /{ }^{\circ} \mathrm{C}\right)$ \\
Relative humidity & $80 \%$ \\
Thermal conductivity & $3.0 \mathrm{~W} / \mathrm{m}^{\circ} \mathrm{C}$ \\
Notional size & $360 \mathrm{~mm}$ \\
Heat transfer coefficient & $7 \mathrm{~W} / \mathrm{m}^{2}{ }^{\circ} \mathrm{C}$ \\
\hline
\end{tabular}

to better control the different variables, the material model is generated with the maturity dependent parameters. This is carried out for elastic modulus, Poisson ratio and shrinkage, including also its own creep function and strength gain based on maturity for a potential crack analysis. The required material properties as input parameters in Diana software are listed in Table 2.

C. Boundary conditions. Two aspects of boundary conditions are considered: (1) structural restraint (2) thermal restraint. The structural translation restraint in an upward direction $\left(\mathrm{U}_{\mathrm{z}}=0\right)$ is applied at the bottom face of the concrete slab assuming that a stiffer base layer is lying below the concrete slab. No friction is assumed between the slab and base. The double symmetry of the geometry is taken along $\mathrm{X}$-axis and $\mathrm{Y}$-axis in order to reduce computation time.

Along the width of CRCP segment, the translation in Xdirection $\left(\mathrm{U}_{\mathrm{x}}=0\right)$ is applied at the symmetry faces as shown in Figure 3. This translates that concrete can contract, but it cannot expand because of the infinite surrounding concrete. Same structural restraint is imposed along the length. For the thermal problem, the top and edge faces of slab are considered to be directly exposed to environment load.

D. Analysis type. Staggered structural-flow analysis is performed to study the early-age behavior of CRCP under environmental load. In the first part of analysis, the structural 


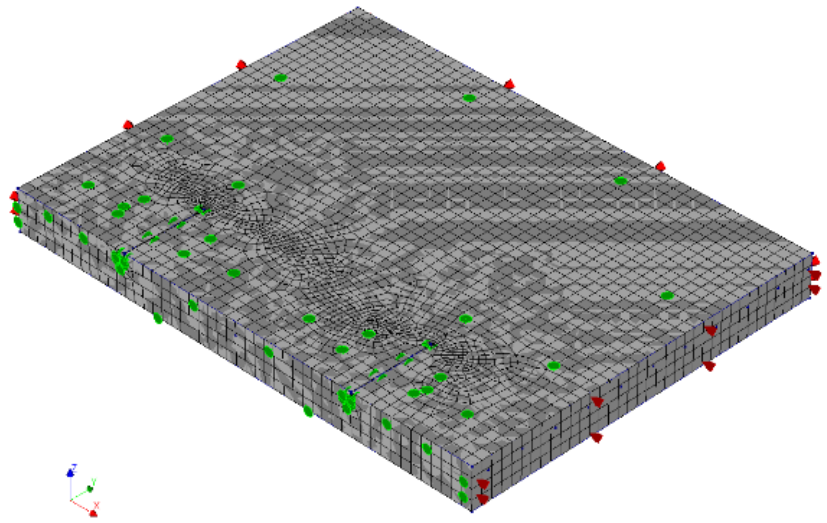

Fig. 3. Boundary conditions of FE model

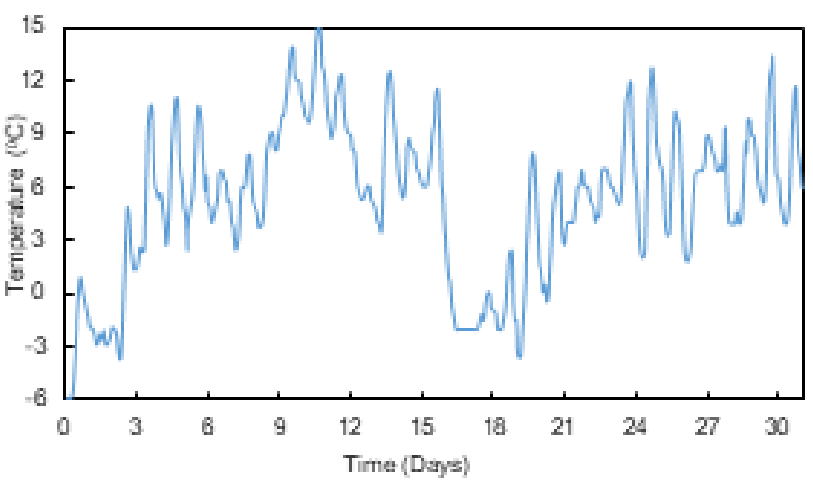

Fig. 4. External temperature load

elements are transformed into flow elements. Then, temperature output from transient heat flow analysis is used as input for structural nonlinear analysis acting as thermal strains. The following environmental load applied to the model is shown in Figure 4.

\section{Results and discussions}

The development of the crack pattern, the vertical concrete stress in the vicinity of longitudinal reinforcing steel and the steel stress in the $3^{\text {rd }}$ and $7^{\text {th }}$ longitudinal bars are studied.

A. Crack pattern. In both models, the cracks initiate from the tip of saw cut and propagate along the width of the pavement
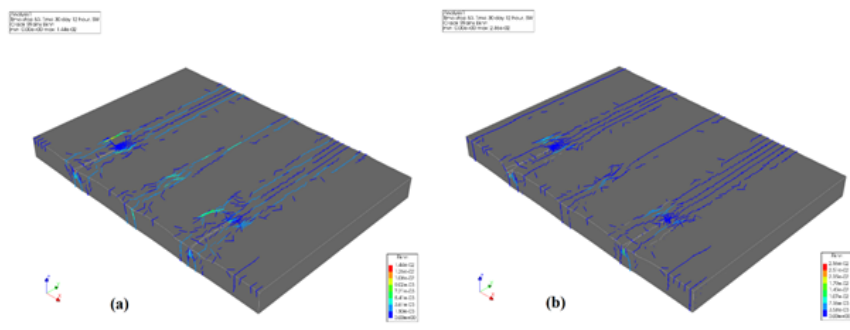

Fig. 5. Transverse crack pattern in a CRCP segment with (a) Conventional steel spacing (b) Varying steel spacing

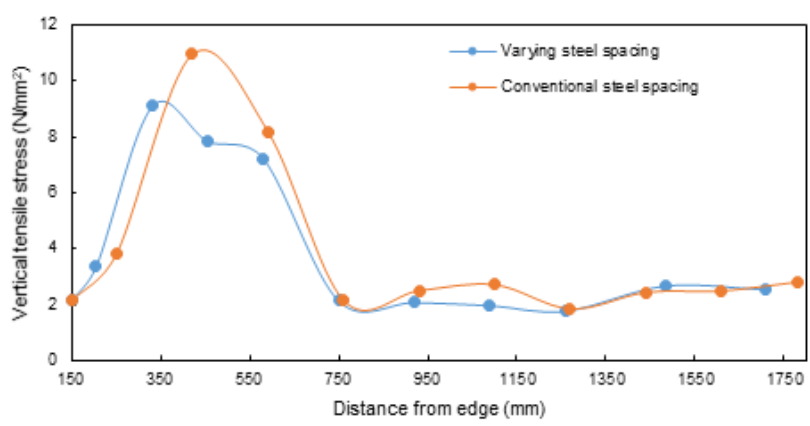

Fig. 6. Vertical tensile stress in the vicinity of longitudinal steel

slab which complies to the field results of CRCPs sections in Belgium $[12,17]$. After the 30 days of concrete pouring, the development of crack pattern in FE models is depicted in Figure 5.

It can clearly be observed that the cracks followed the direction of the transverse steel which means that the mean crack spacing is identical to the design spacing of the transverse reinforcing bar. FE model with conventional longitudinal steel spacing exhibits more severe cracking in the outer region of the pavement slab as well as in the central part of CRCP segment in comparison to $\mathrm{FE}$ model with varying longitudinal steel spacing as illustrated in Figure 5. In case of varying steel spacing, cracking occurs throughout the width in the left extreme region of CRCP segment. The possible reason behind it could be the higher longitudinal steel restraint because of the narrow steel spacing in the exposed outer region of CRCP segment directly to environmental conditions.

B. Concrete stress in the vicinity of the steel. Horizontal cracking occurs due to the development of vertical concrete stress in the vicinity of longitudinal reinforcing steel bars at the transverse crack interface which ultimately leads to the punch-out distress in the outer region of the pavement.

The present study is mainly focused on the development of vertical concrete stress in the vicinity of longitudinal steel with varying steel spacing. Figure 6 illustrates the variations in vertical concrete stress in both FE models. It can clearly be observed that the maximum vertical concrete stress near the longitudinal steel occurs in the outer region of CRCP segment which ranges from 0 to $750 \mathrm{~mm}$. FE model with conventional steel spacing produces the maximum vertical concrete stress of $10.96 \mathrm{MPa}$ which is $17 \%$ greater than that of FE model with the narrow steel spacing in the outer region of the pavement slab. It translates that the amount of vertical stress in concrete near longitudinal steel could be effectively reduced by using the narrow steel spacing in the outer part of the concrete slab.

C. Stress in the longitudinal steel. In order to see the distribution of stress in steel, the $3^{\text {rd }}$ and $7^{\text {th }}$ longitudinal reinforcing bars with respect to the entire model of CRCP segment are selected for the comparison purpose. Contrary to FE model with conventional steel spacing, the four peaks of stress occur in FE model with varying longitudinal steel spacing as illustrated in Figure 7 . Three peaks occur exactly over the location of the transverse reinforcing bars. Peak occurs in the left extreme end of the steel bar could be due to the higher longitudinal restraint against the dry shrinkage of concrete. 


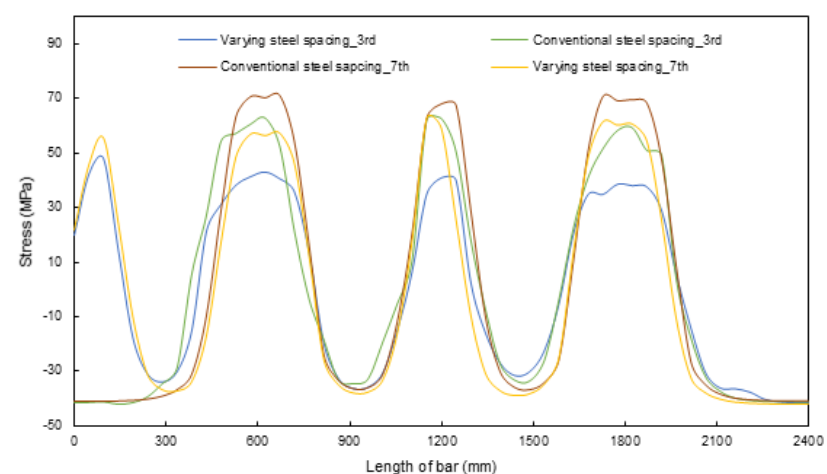

Fig. 7. tress in the $3^{\text {rd }}$ and $7^{\text {th }}$ longitudinal steel bar

CRCP segment with conventional steel spacing exhibits the average maximum tension stress of $62.11 \mathrm{MPa}$ and 69.95 $\mathrm{MPa}$ in the $3^{\text {rd }}$ and $7^{\text {th }}$ longitudinal steel bars respectively and that with varying steel spacing produces $42.39 \mathrm{MPa}$ and $59.22 \mathrm{MPa}$ respectively. So, the stress is reduced by $31.75 \%$ in the outer region of the pavement slab with the use of narrow steel spacing. Additionally, it also causes a reduction in stress in the center of CRCP segment by $15 \%$.

\section{Findings}

1. Cracking initiates from the tip of saw cut and propagates along the width of the pavement slab following the direction of the transverse reinforcing steel which is in good agreement with the field observations.

2. FE model with conventional steel spacing exhibits more severe cracking in the outer and central region of CRCP segment in comparison to $\mathrm{FE}$ model with varying steel spacing.

3. Concrete stress in the vicinity of longitudinal steel bars in the outer region of the segment is reduced up to maximum $17 \%$ with the use of narrow steel spacing.

4. Steel stress in the outer region of CRCP segment is reduced up to maximum $31.75 \%$ by using varying longitudinal steel.

\section{Future work}

The implementation of varying longitudinal steel in CRCP needs further investigation and validation by large scale field testing.

1. Hall, K., et al., Long-life concrete pavements in Europe and Canada. 2007.

2. Verhoeven, K. Cracking and corrosion in continuously reinforced concrete pavements. in Fifth International Conference on Concrete Pavement Design and Rehabilitation Purdue University, School of Civil Engineering; Federal Highway Administration; Portland Cement Association; Transportation Research Board; Indiana Department of Transportation; Federal Aviation Administration; and American Concrete Pavement Association. 1993.

3. Chen, D.-H., H.-H. Lin, and R. Sun, Field performance evaluations of partial-depth repairs. Construction and Building Materials, 2011. 25(3): p. 1369-1378.

4. Choi, S., S. Ha, and M.C. Won, Horizontal cracking of continuously reinforced concrete pavement under environmental loadings. Construction and Building Materials, 2011. 25(11): p. 4250-4262.
5. Darter, M.I., S.A. LaCoursiere, and S.A. Smiley, Structural Distress Mechanisms in Continuously Reinforced Concrete Pavement. Transportation Research Record, 1979(715).

6. Kim, K., et al., Optimization of parameters affecting horizontal cracking in continuously reinforced concrete pavement (CRCP). Canadian Journal of Civil Engineering, 2019. 46(7): p 634-642.

7. Kim, S.-M. and M.C. Won, Horizontal cracking in continuously reinforced concrete pavements. Structural Journal, 2004. 101(6): p. 784-791.

8. Zollinger, D.G., Investigation of punchout distress of continuously reinforced concrete pavement. 1990.

9. Kim, S.-M., M.C. Won, and B. Frank McCullough, Three-dimensional analysis of continuously reinforced concrete pavements. Transportation Research Record, 2000. 1730(1): $p$ 43-52.

10. Rasmussen, R.O., R. Rogers, and T.R. Ferragut, Continuously reinforced concrete pavement design \& construction guidelines. Technical Manual, Federal_Highway Administration and Concrete Reinforcing Steel Institute, Washington, DC and Schaumburg, IL. . crsi. org/transportation/fhwa_crcp/pdf/CRCP_Design-Const_Manual [draft]. pdf, 2009.

11. Ren, D., L. Houben, and L. Rens, Cracking behavior of continuously reinforced concrete pavements in Belgium: characterization of current design concept. Transportation Research Record, 2013. 2367(1): p. 97-106.

12. Ren, D., L.J. Houben, and L. Rens, Monitoring early-age cracking of continuously reinforced concrete pavements on the E17 at Ghent (Belgium), in Sustainable Construction Materials 2012. 2013. p. 30-41.

13. Rens, L. Continuously Reinforced Concrete-State-of-the-Art in Belgium. in Proc., 11th International Symposium on Concrete Roads. 2010.

14. Rens, L. and A. Beeldens. The Behaviour of CRCP in Belgium: Observation and Measurement of Crack Pattern, Bond and Thermal Movement. in Proc., 7th International DUT-Workshop on Design and Performance of Sustainable and Durable Concrete Pavements. 2010.

15. Rens, L., P. Winne, and A. Beeldens. Continuously Reinforced Concrete Pavement: New Development for a Sustainable Concept. in Belgian Road Congress, Liege, Belgium. 2013.

16. De Winne, P., H. De Backer, and S. Depuydt, Active crack control in continuously reinforced concrete pavements (CRCP), in High Tech Concrete: Where Technology and Engineering Meet. 2018, Springer. p. 1389-1397.

17. Ren, D., et al., Active Crack Control for Continuously Reinforced Concrete Pavements in Belgium Through Partial Surface Notches. Transportation Research Record, 2014. 2456(1): p 33-41.

18. Al-Qadi, I.L. and M. Elseifi, Mechanism and modeling of transverse cracking development in continuously reinforced concrete pavement. International Journal of Pavement Engineering, 2006. 7(4): p. 341-349

19. Choi, S., B.-U. Na, and M.C. Won, Mesoscale analysis of continuously reinforced concrete pavement behavior subjected to environmental loading. Construction and Building Materials, 2016. 112: p. $447-456$. 